The magazine sounded great, I was told, but unfortunately there were no PCDs working at that particular practice - just the dental team.

\title{
Professionals vital to dentistry
}

This issue sees the launch of the $B D J$ 's new regular supplement for PCDs, Vital.

The dental team has become increasingly important in recent years, and with the extension of duties for hygienists and therapists and the upcoming registration of dental nurses and technicians, we felt the time was right for a publication for the whole dental team.

With Vital, we aim to promote understanding between all team members while providing relevant information for each specialty.

Why Vital? Because contrary to what the term PCD suggests, team members are not only complementary to dentistry, but, in fact, vital to any effective practice. We also hope the magazine will become vital reading for dental nurses, technicians, hygienists, practice managers, receptionists and therapists.

While researching for the new supplement, it soon became apparent that many team members resent the term PCD. The first hint of this was at the GDC's PCD Roadshow in Newmarket, an evening set aside to educate PCDs about the new registration guidelines. During the introduction, the speaker mentioned his dislike of the term, and an audible groan of agreement swept through the audience.

The unpopularity of the name appears to be compounded by a genuine confusion as to what the term means. When I took time out to visit practices and describe our idea of a supplement for PCDs, I received warm but slightly baffled responses. The magazine sounded great, I was told, but unfortunately there were no PCDs working at that particular practice - just the dental team.

How can it be that a term that is so commonly bandied about in dental circles and littered throughout the dental press remains so mysterious to the group it actually describes? And why did I not realise until now?

After almost five years of working on the $B D J$, I thought I knew the dental world well. But it took something like this, a new publication, to get me out of the office and into the practices, and to talk to the teams who are doing the job for real. It is like anything in life, it is easy to assume we know what's going on and carry on regardless. But sometimes it pays to stop and ask - you might just be surprised what you find.

Of course this uncertainty as to what a PCD is was not found at every practice, but it happened often enough to set me thinking - if the term is so disliked and so misunderstood, where did it come from?

Apparently, the term was first put forward by the GDC's Dental Auxilaries Review Group in the 1990s as a replacement for the term 'Personnel Auxiliary to Dentistry'. It was felt the new term gave more weight to the role played by dental auxilaries, and was embraced by the GDC. The BDA followed suit, changing the name of the BDA Dental Auxiliaries Committee to the BDA Professionals Complementary to Dentistry Committee. PCDs were born. To add to the confusion, the term 'Dental Auxiliaries' is still in existence, as it is enshrined in the 1984 Dentists Act.

The acronym PED - Professionals Essential to Dentistry - has become popular in recent times and may one day supercede the term PCD. Whatever the name, the importance of each group is certainly growing, and statutory registration is just the beginning of team members receiving the recognition they deserve. We hope by naming our supplement Vital we will help to increase this recognition.

There will be four issues of Vital in 2004. While the magazine is aimed at team members, we feel sure the supplement will be a source of interest to dentists as team leaders as well.

Whether this $B D J$ has come to your home address or your practice, please ensure that everyone in the dental team - be they PCDs, PADs or PEDs - get to see Vital too.

Kate Craig,

Editor, Vital

k.craig@bda.org

doi:10.1038/sj.bdj.4810658 